\title{
BMJ Open Improving the uptake of systematic reviews: a systematic review of intervention effectiveness and relevance
}

\author{
John Wallace, ${ }^{1}$ Charles Byrne, ${ }^{2}$ Mike Clarke ${ }^{1}$
}

To cite: Wallace J, Byrne C, Clarke M. Improving the uptake of systematic reviews: a systematic review of intervention effectiveness and relevance. BMJ Open 2014;4: e005834. doi:10.1136/ bmjopen-2014-005834

- Prepublication history and additional material is available. To view please visit the journal (http://dx.doi.org/ 10.1136/bmjopen-2014005834)

Received 10 June 2014 Revised 4 September 2014 Accepted 15 September 2014

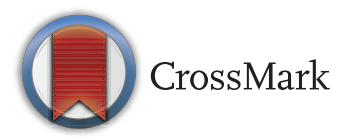

${ }^{1}$ Department of Continuing Education, Wellington Square, Oxford, UK ${ }^{2}$ Department of Psychiatry, Roscommon County Hospital, Roscommon, Ireland

Correspondence to Dr John Wallace; john.wallace@wadh.oxon.org

\section{ABSTRACT}

Objective: Little is known about the barriers, facilitators and interventions that impact on systematic review uptake. The objective of this study was to identify how uptake of systematic reviews can be improved.

Selection criteria: Studies were included if they addressed interventions enhancing the uptake of systematic reviews. Reports in any language were included. All decisionmakers were eligible. Studies could be randomised trials, cluster-randomised trials, controlled-clinical trials and before-and-after studies.

Data sources: We searched 19 databases including PubMed, EMBASE and The Cochrane Library, covering the full range of publication years from inception to December 2010. Two reviewers independently extracted data and assessed quality according to the Effective Practice and Organisation of Care criteria.

Results: 10 studies from 11 countries, containing 12 interventions met our criteria. Settings included a hospital, a government department and a medical school. Doctors, nurses, mid-wives, patients and programme managers were targeted. Six of the studies were geared to improving knowledge and attitudes while four targeted clinical practice.

Synthesis of results: Three studies of low-tomoderate risk of bias, identified interventions that showed a statistically significant improvement: educational visits, short summaries of systematic reviews and targeted messaging. Promising interventions include e-learning, computer-based learning, inactive workshops, use of knowledge brokers and an e-registry of reviews. Juxtaposing barriers and facilitators alongside the identified interventions, it was clear that the three effective approaches addressed a wide range of barriers and facilitators.

Discussion: A limited number of studies were found for inclusion. However, the extensive literature search is one of the strengths of this review.

Conclusions: Targeted messaging, educational visits and summaries are recommended to enhance systematic review uptake. Identified promising approaches need to be developed further. New strategies are required to encompass neglected barriers and facilitators. This review addressed effectiveness and also appropriateness of knowledge uptake strategies.

\section{Strengths and limitations of this study}

- Strengths included an extensive search of 19 databases.

- The review had added value by drawing on 27 barrier and 15 facilitator studies.

- Both effectiveness and appropriateness are addressed.

- However, just 10 intervention studies were detected.

\section{INTRODUCTION}

Although the importance of research evidence is largely unquestioned intellectually, medical practice often diverges from evidence-based recommendations. This denies patients the benefits of medical research. ${ }^{1}$ Despite initiatives to improve the use of research findings, variation in the uptake of evidence exists. ${ }^{2}$ The communication of clinically important research is hampered by the volume and geometric growth of the medical literature. Systematic reviews can address this problem and are a good way of taming the evidence. ${ }^{3}$ A systematic review is a 'review of a clearly formulated question that uses systematic and explicit methods to identify, select and critically appraise relevant research and to collect and analyse data from studies that are included in the review' ${ }^{4}$

Evidence from systematic reviews however has not been widely adopted by healthcare professionals. $^{5}$ A review of physicians' information-seeking behaviour found that textbooks are the most frequently used source of information, followed by advice from colleagues. ${ }^{6}$ Systematic reviews were never cited as the source of research evidence when such evidence was used by policymakers and healthcare managers. ${ }^{7}$ Research into interventions for enhancing the uptake of evidence by clinical practitioners and by policymakers indicate that further examination of the issue is warranted. ${ }^{89}$ 
The creation of systematic reviews without attention to their uptake is clearly a sterile exercise. Systematic reviews were the focus of this investigation, rather than the more commonly investigated clinical practice guidelines or individual, primary studies. Systematic reviews are based on primary research while clinical practice guidelines are an amalgam of clinical experience, expert opinion, patient preferences and evidence. Systematic reviews are a scientific exercise aimed at generating new knowledge and they provide a summary of relevant primary research. In this way, they can help keep us current. Systematic reviews have a distinct development and scientific purpose that differs from both guidelines and primary research. Given the considerable differences between integrative reviews and clinical practice guidelines, we set out to identify factors enhancing the uptake specifically of systematic reviews and meta-analyses.

The current authors had previously identified the barriers ${ }^{10}$ and also the facilitators ${ }^{11}$ impacting on systematic review uptake. Outcome studies of interventions that attempt to enhance systematic review uptake were now addressed. Uptake encompassed an increase in awareness, familiarity and intellectual adoption as well as practical use in decision-making, giving this review a broader focus than previous work in the area. ${ }^{2} 89$ Nor were the decisionmakers included in this review limited to any specific background as occurs in other reviews. ${ }^{2} 89$

Importantly, a further synthesis was also carried out integrating the previously identified barriers and facilitators with the newly selected interventions detected in our systematic review. This study was needed in order to identify strategies that can be used to improve systematic review uptake. By drawing on our previous barrier and facilitator research, the appropriateness of these newly identified interventions can now also be estimated. This review has added value. Having assessed not just the effectiveness but also the relevance of the detected interventions, recommendations can now be made about the use of specific strategies to improve systematic review uptake.

There are challenges however to synthesising such diverse evidence sources. ${ }^{12}$ A hybrid approach was used here to address different but related elements of an overall review question. ${ }^{13}$ Separate syntheses of intervention but also non-intervention studies, with an overall narrative commentary, are described.

The studies to be included in our review were diverse. For barriers and natural facilitators, the reports included surveys, focus groups and interviews. ${ }^{10} 11$ However, intervention studies were also included in the final overarching synthesis. So results from qualitative studies were juxtaposed with results of randomised-controlled trials. Data was extracted from these disparate studies and a synthesis carried out. ${ }^{14}$

Attention to other vantage points that decisionmakers adopt when confronted with an innovation is important. ${ }^{15}$ The aim here was to illuminate a complex area from different angles. ${ }^{16}$ The objective was also to identify gaps in existing research evidence. ${ }^{17}$ Narrative synthesis provided a summary of the current state of knowledge where recommendations could then be made for enhancing uptake of evidence from systematic reviews. ${ }^{13}$

\section{Method}

\section{Search strategy}

We conducted a systematic review of the literature to identify interventions to enhance evidence uptake from systematic reviews, meta-analyses and the databases containing them. The primary researcher (JW) searched 19 databases and used 3 search engines, for articles, not limited to the English language and covering the full range of publication years available in each database up to December 2010 using a combination of index terms and text words derived from relevant articles previously identified.

The databases searched included the Cochrane Library, TRIP, Joanna Briggs Institute, National Guideline Clearing House, Health Evidence, PubMed (1950-December 2010), EMBASE (1980-December 2010), ERIC, CINAHL, PsycInfo, OpenSigle, Index to Theses in Great Britain and Ireland and Conference Papers Index, Campbell Collaboration, Canadian Health Services Research Foundation, Cochrane Effective Practice and Organisation of Care Group (EPOC), KT+, McMaster University, Keenan Research Centre and the New York Academy of Medicine. The search engines ALTA VISTA and Google Scholar were also utilised with a special emphasis on grey and knowledge translation literature. References from included primary studies and related review articles were scanned, experts in the field contacted and bibliographies of textbooks were reviewed. A combination of index terms and text words was used generated by the structured research question. A wide range of synonyms for uptake were combined with various terms for synthesis and systematic reviews, together with synonyms for improvement. Search terms, including systematic review and meta-analysis, were combined with terms for interventions or uptake, together with the synonyms for improve or enhance. A wide range of search terms was employed including facilitator, incentive, improve, enhance, disseminate, utilise, translate, uptake, intervention, overview, systematic review and meta-analysis. The search terms, using truncation, were linked into the search strategy using Boolean operators. The strategy was broadened or narrowed depending on need or result when applied to the different databases listed. Uptake encompassed connectivity, awareness, familiarity, adoption, use and healthcare outcomes.

We repeated parts of the search for the period January 2011 to January 2014 in order to identify any potentially relevant or on-going studies. We applied the same search strategies to PubMed and EMBASE, the two most productive databases in terms of studies identified for inclusion in the review. We also searched all active 
registers in the metaRegister of controlled trials (http:// www.controlledtrials.com/mrct/), in January 2014, for reports of relevant on-going or completed trials, to be listed under 'On-going studies' and 'Studies awaiting classification' that could be included in an update of this review.

\section{Selection criteria}

Two review authors independently assessed studies for inclusion; discrepancies were resolved by discussion or by a third party. Studies with no clear relation to systematic review uptake were excluded. We included studies if they were an original collection of data.

\section{Inclusion criteria}

To be included in the review, primary studies had to meet the following criteria:

- Addressed interventions aimed at increasing the uptake of evidence specifically from systematic reviews, meta-analyses and the databases that contained them;

- Databases could include The Cochrane Library, The Cochrane Database of Systematic Reviews, Database of Abstracts of Reviews of Effects, Cochrane Pregnancy and Childbirth Database, Oxford Database of Perinatal Trials and the Reproductive Health Library;

- All decisionmakers, including doctors, nurses, policymakers, the public and patients, were eligible

- Reports in any language were included;

- Studies could be randomised trials, cluster randomised trials, controlled clinical trials and before-and-after studies;

- Interventions could arise from within the research community or from within an organisation using systematic review evidence;

- Strategies could be single-stranded or multifaceted, or combine two or more interventions;

- The mode of delivery of the intervention could be print, electronic, audio/visual or face-to face;

- When a comparison was employed, the comparator could be no intervention or an alternative intervention;

- It was not required that the interventions be specifically tailored to overcome specified, preidentified barriers;

- Measures of impact on knowledge, attitude, behaviour or patient care were included.

'Uptake' can refer to an increase in awareness, familiarity, adoption, as well as actual use of evidence. While measures of impact on knowledge, attitude or use of reviews were included, impact on patient care was also encompassed. Any outcome measure of the utilisation of systematic review evidence informing healthcare decision-making was considered. Self-reported use of evidence was included as well as outcome measures of practical use. Interventions could arise from within the research community or from within an organisation using systematic review evidence. Strategies to enhance uptake of policy briefs, position statements or clinical practice guidelines were excluded.

Care was also taken to identify studies that produced multiple publications. When more than one report described a single study and each presented the same data, only the most recent publication was included. However, if more than one publication described a single study but each presented new and complementary data, both were included.

\section{Data collection and analysis}

Two reviewers (JW and $\mathrm{CB}$ ) independently abstracted specific information from full-text studies according to standardised data extraction checklist items derived from Cochrane Effective Practice and Organisation of Care criteria checklists. ${ }^{18}$ Discordances between the two reviewers were resolved by consensus. Two reviewers assessed the risk of bias of included studies using criteria described by EPOC. For all of the studies included in the review, we assigned an overall risk of bias rating such as high, moderate and low based on the standard criteria used in EPOC reviews.

Strategies with a non-significant, a negative effect or did not meet the study objectives, compared with the primary objective of the authors, were classified as 'ineffective'; 'mixed effects' was ascribed to studies that partially reached their objectives; and strategies with a significant, positive effect were classified as 'effective'. ${ }^{\text {, }}$ No meta-analysis was performed because of the high heterogeneity between the outcomes of each study. ${ }^{20}$ Reviews of research-to-action strategies add up the number of positive and negative comparisons and conclude whether interventions were effective on that basis. $^{21}$

\section{Assessment of risk of bias}

Two reviewers assessed the risk of bias of included studies using criteria described by EPOC. Given the potential heterogeneity of the targeted behaviours, skills, and organisational factors relevant to the review, this reviewer did not base study inclusion on a minimum cut-off for methodological quality. For all of the studies included in the review, this reviewer assigned an overall risk of bias rating such as high, moderate and low, based on the standard criteria used in EPOC reviews. We assigned a rating of low risk of bias if the first three criteria were scored as done and there were no concerns related to the last three criteria; moderate if one or two criteria were scored as not clear or not done; and high if more than two criteria were scored as not clear or not done. ${ }^{22}$ Each criterion was noted 'Done,' 'Not clear,' or 'Not done'. Only studies with a low to moderate risk of bias were used to draw conclusions about effectiveness of interventions to enhance uptake of reviews. 


\section{Data synthesis}

There is a tendency for more recent systematic reviews to include a wider range of diverse study designs. ${ }^{23} \mathrm{~A}$ broader focus is now advocated. ${ }^{15}$ Research findings on barriers and facilitators impacting on review uptake can help in the development of potentially effective intervention strategies. The interventions can modify or remove barriers and use and build on existing facilitators to enhance evidence uptake. Following formal identification of strategies to improve uptake of systematic reviews, these interventions were then juxtaposed with previously highlighted barriers and facilitators.

A framework for including different types of evidence in systematic reviews was used here. ${ }^{13}$ This approach has been successfully applied elsewhere. ${ }^{24-27}$ Using a mixedmethods approach, three types of analyses were performed. These included a synthesis of non-intervention studies, a synthesis of intervention outcome evaluations and lastly a synthesis of the intervention and noninterventions studies together. For the last of these, a matrix was constructed which laid out the barriers and facilitators alongside descriptions of the interventions included in the in-depth systematic review of outcome evaluations. It was thus possible to see where barriers have been modified, or facilitators built on, by relatively sound interventions. It was also possible to identify promising interventions that need further assessment. ${ }^{13}$ Furthermore, it was practical to ascertain where factors had not been addressed by any approach, necessitating the development of new interventions.

The initial purpose of this review was to identify interventions that improve uptake of systematic reviews. The next objective was to ascertain whether the detected interventions addressed issues important to decisionmakers. This allowed a utilisation of views on barriers and facilitators as a marker of the appropriateness of different interventions. ${ }^{13}$

\section{RESULTS}

The results of the extensive search for studies addressing interventions that enhance uptake of systematic reviews are given in figure 1 .

\section{Results of the search}

Some 1564 records were identified through database searching covering the full range of publication years available in each of the 19 database up to December 2010 and 50 records identified through other sources, such as bibliographies of related reviews and primary studies, textbooks and contact with authors. Of the total number of 1614 titles and abstracts screened from all sources, including qualitative and grey literature searching, 1524 records were excluded as not meeting inclusion criteria. Then 90 full-text articles were retrieved and assessed for eligibility. Some 62 studies were excluded as they did not address systematic reviews or meta-analysis, 3 were duplicate studies and 15 studies were excluded and analysed separately as they addressed natural, non-intervention facilitators derived from surveys, focus groups and interviews. ${ }^{11} \mathrm{~A}$ selective list of studies excluded after reading the full text is given as a online supplementary file. Ten intervention studies were included and form the substrate for this review (table 1).

A further search of EMBASE and PubMed from January 2011 to January 2014 yielded 248 and 387 records, respectively but failed to identify any further relevant studies. The metaRegister of controlled trials was also searched in January 2014 and no study was identified for inclusion in 'Studies awaiting classification' or 'On-going studies'. An example the search strategies utilised is given in table 2.

\section{Included studies}

Of the ten included intervention studies, this researcher counted 5 randomised controlled trials, 3 cluster randomised controlled trials, 1 controlled clinical trial and 1 before-after study. ${ }^{28-37}$ There were 8 two-arm trials, 1 single-arm trial and 1 three-armed trial. The unit of allocation was the health professional, such as a doctor, in 3 studies, the patient in 1 report and a larger grouping such as the hospital or geographical location in 6 studies.

\section{Settings and characteristics of professionals}

The nature of the desired change, professionals targeted and the settings, differed from one intervention study to the next. Four studies were undertaken in the UK, 1 each in Australia, USA and Canada while 1 study was conducted across five countries: Germany, Hungary, Spain, Switzerland and the UK. The remaining 2 studies were carried out in the Netherlands and the UK, and in Mexico and Thailand, respectively. The studies were conducted in 11 countries in total.

Eight of the intervention studies took place in a hospital setting while the remaining two investigations were conducted in a government department and a medical school. In 6 of the studies, the professionals included doctors of different subspecialities and at varying stages of training. Two studies dealt with obstetricians, 1 study included psychiatrists, another general practitioners and 2 studies involved Interns (Foundation year). Three reports included nurses or mid-wives, one targeted patients as participants exclusively, while another looked at programme managers.

\section{Prospective identification of barriers to change}

None of the 10 studies tailored the intervention to prospectively identified barriers to uptake of evidence from systematic reviews or meta-analyses.

\section{Theoretical underpinning}

Eight studies identified a theoretical underpinning to their choice of intervention. One study included a costing for their intervention to improve uptake of evidence from systematic reviews. ${ }^{28}$ 
Figure 1 PRISMA flow diagram.

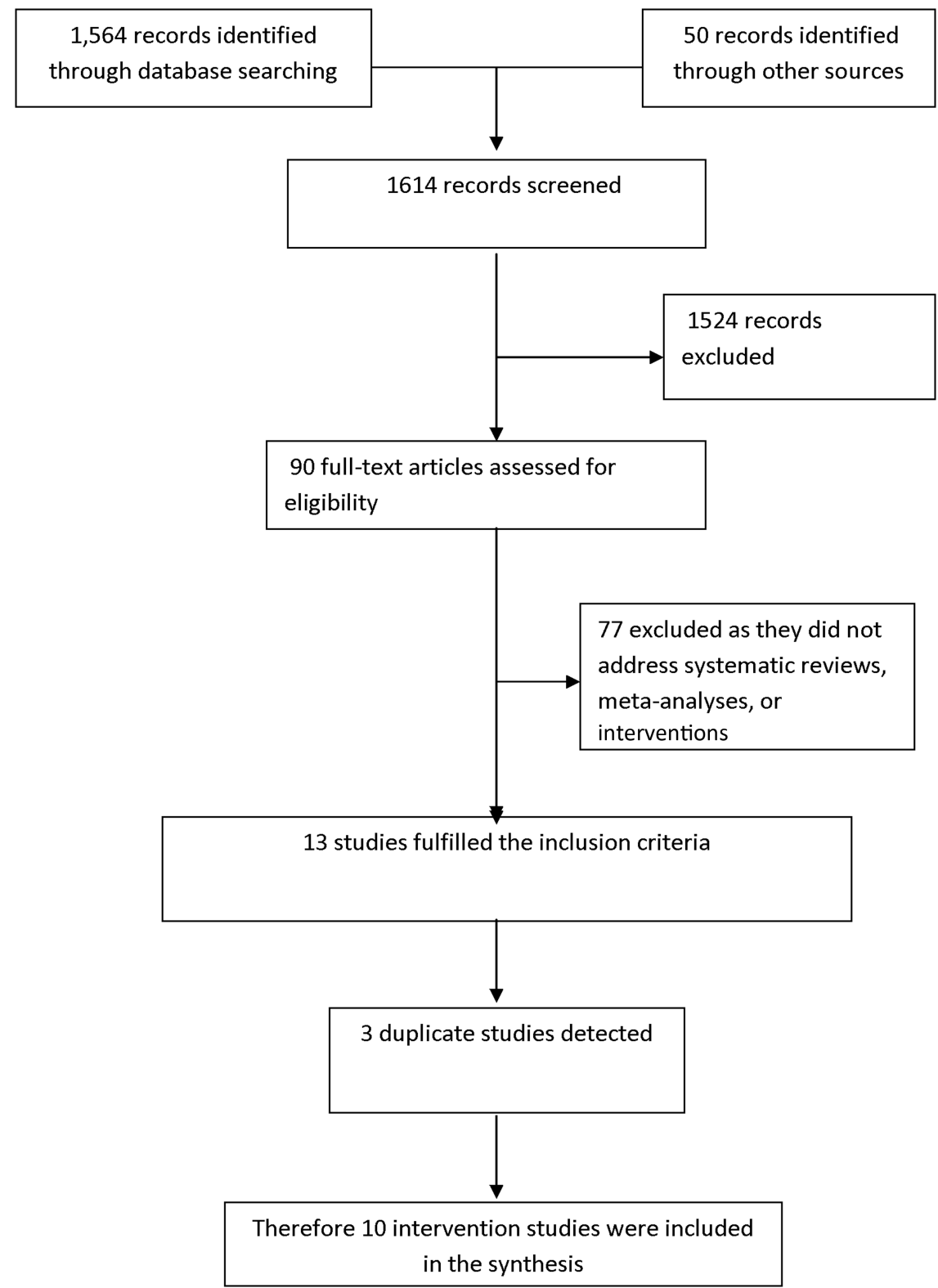

\section{Characteristics of interventions}

Among these reports, interventions included clinically integrated e-learning courses (3/10), educational visits $(2 / 10)$, a computer-based (CD-ROM) session focusing on critical appraisal of systematic reviews (2/10), brief summaries of systematic reviews $(1 / 10)$, a manual of Cochrane reviews $(1 / 10)$ and access to an online registry, tailored messaging and use of knowledge brokers $(1 / 10)$. Descriptions of the strategies are outlined in table 1 . One study investigated three interventions. ${ }^{33}$

\section{Risk of bias in included studies}

Of the 10 included studies, 8 had addressed allocation concealment. Follow-up of professionals was carried out adequately in 6 studies. Blinded assessment of the primary outcome was carried out in 9 studies. Baseline measurement was conducted adequately in 5 studies. A reliable primary outcome measure was reported in all
10 studies. Protection against contamination was assessed by us as adequate in 7 studies. Regarding the overall risk of bias, 2 studies were assessed as being at high risk, ${ }^{34} 35$ two at low risk of bias, ${ }^{28} 32$ while 6 studies were regarded as being of moderate risk of bias. ${ }^{29-31} 333637$

\section{Outcomes}

Use of correct outcome measures in this area is of considerable importance. ${ }^{38}$ Six studies were concerned with changing knowledge and attitudes. One report analysed both knowledge and decisionmaker behaviour ${ }^{30}$ while another $^{31}$ addressed practice and quality of life. Two studies analysed specific practice change (table 3). ${ }^{28} 33$

Three studies, of low-to-moderate risk of bias, showed a statistically significant improvement on some relevant outcome. These interventions included educational visits, $^{28}$ short summaries of systematic reviews ${ }^{29}$ and targeted messaging. ${ }^{33}$ 
Table 1 Characteristics of included studies $(n=10)$

\begin{tabular}{|c|c|c|}
\hline $\begin{array}{l}\text { Study } \\
\text { Location } \\
\text { Design }\end{array}$ & $\begin{array}{l}\text { Strategy } \\
\text { Participants } \\
\text { Setting }\end{array}$ & Description \\
\hline $\begin{array}{l}\text { Wyatt et al } \\
\text { UK } \\
\text { RCT }\end{array}$ & $\begin{array}{l}\text { Educational visit to obstetricians and } \\
\text { mid-wives in } 25 \text { district obstetric units }\end{array}$ & $\begin{array}{l}\text { Educational visit (single) by a respected } \\
\text { obstetrician advancing general ways to apply } \\
\text { evidence from Cochrane reviews with The } \\
\text { Cochrane database donated. } \\
\text { Visit to lead obstetrician and mid-wife on } \\
\text { labour ward }\end{array}$ \\
\hline Gulmezoglu et $a^{30}$ & Multifaceted intervention: interactive & 3 interactive workshops using RHL over \\
\hline $\begin{array}{l}\text { Mexico, Thailand Cluster } \\
\text { randomised trial }\end{array}$ & $\begin{array}{l}\text { workshops in } 40 \text { maternity units in } \\
\text { non-academic hospitals including doctors, } \\
\text { mid-wives, interns and students }\end{array}$ & $\begin{array}{l}6 \text { months, focusing on access and use with the } \\
\text { focus on the RHL contents in general }\end{array}$ \\
\hline $\begin{array}{l}\text { Harris et } a^{\beta 1} \\
\text { Australia Controlled clinical } \\
\text { trial }\end{array}$ & $\begin{array}{l}\text { Patient manual to doctor's patients in } 3 \\
\text { hospitals }\end{array}$ & $\begin{array}{l}\text { Patient manual of summaries of Cochrane } \\
\text { reviews: } 80 \text { page, A5 size manual with } 22 \\
\text { summaries of evidence organised into easy to } \\
\text { find sections }\end{array}$ \\
\hline $\begin{array}{l}\text { Oermann et af } \\
\text { USA } \\
\text { RCT }\end{array}$ & $\begin{array}{l}\text { Short summary of systematic review to } 50 \\
\text { nurses in medical and surgical units in seven } \\
\text { hospitals }\end{array}$ & $\begin{array}{l}\text { Four short, one-page systematic review } \\
\text { summaries delivered by email or mail, on } \\
\text { patient-controlled analgesia }\end{array}$ \\
\hline $\begin{array}{l}\text { Davis et } a \beta^{37} \\
\text { UK } \\
\text { RTC }\end{array}$ & $\begin{array}{l}\text { Computer-based session newly qualified } \\
\text { medical doctors in } 6 \text { postgraduate centres }\end{array}$ & $\begin{array}{l}\text { CD ROM sessions, } 40 \text { min duration, } \\
\text { emphasising critical and application of } \\
\text { systematic reviews and meta-analyses }\end{array}$ \\
\hline $\begin{array}{l}\text { Kulier et } a{ }^{\beta 4} \\
\text { Before-and after-design } \\
\text { Germany, Hungary, Spain, } \\
\text { Switzerland, UK }\end{array}$ & $\begin{array}{l}\text { E-learning course to postgraduate medical } \\
\text { trainees from different specialities in primary } \\
\text { and secondary care }\end{array}$ & $\begin{array}{l}3 \text { e-learning modules focusing on systematic } \\
\text { reviews, with unlimited access over } 6 \text { weeks }\end{array}$ \\
\hline $\begin{array}{l}\text { Davis et a }{ }^{\beta 6} \\
\text { UK } \\
\text { RCT }\end{array}$ & $\begin{array}{l}\text { Computer-based session for medical } \\
\text { undergraduates in a medical school setting }\end{array}$ & $\begin{array}{l}1 \text { computer (CD-ROM) session focusing on } \\
\text { systematic reviews and meta- analyses a } \\
\text { standardised structure of } 40 \mathrm{~min}\end{array}$ \\
\hline $\begin{array}{l}\text { Kulier et } a{ }^{\beta 2} \text { Netherlands } \\
\text { UK } \\
\text { Cluster RCT }\end{array}$ & $\begin{array}{l}\text { E-learning course for postgraduate trainees in } \\
6 \text { obstetrics and gynaecology departments }\end{array}$ & $\begin{array}{l}5 \text { e-learning modules focusing on systematic } \\
\text { reviews, over } 5 \text { weeks with on the job training, } \\
\text { self-directed learning }\end{array}$ \\
\hline $\begin{array}{l}\text { Dobbins et } a \mathrm{l}^{33} \\
\text { Canada } \\
\text { RCT }\end{array}$ & $\begin{array}{l}\text { Tailored, targeted messaging, on-line registry, } \\
\text { knowledge broker to } 108 \text { health departments: } \\
\text { programme managers, programme } \\
\text { coordinators and programme directors }\end{array}$ & $\begin{array}{l}\text { Messages from } 7 \text { rigorous systematic reviews. } \\
\text { A series of emails with link to full reference, } \\
\text { abstract and summary. Also a visit from } \\
\text { knowledge broker and access an on-line } \\
\text { registry }\end{array}$ \\
\hline $\begin{array}{l}\text { Hadley et } a{ }^{\beta 5} \\
\text { UK } \\
\text { Cluster RCT }\end{array}$ & $\begin{array}{l}\text { E-learning course focusing on systematic } \\
\text { reviews with postgraduate doctors at } \\
\text { internship level in } 7 \text { teaching hospitals }\end{array}$ & $\begin{array}{l}\text { Clinically integrated e-learning EBM course } 3 \\
\text { modules involving critical appraisal of } \\
\text { systematic reviews, unlimited access over } \\
6 \text { weeks }\end{array}$ \\
\hline
\end{tabular}

RCT, randomised controlled trial; RHL, Reproductive Health Library.

Other interventions such as interactive workshops produced 'substantial' benefits. ${ }^{30}$ Clinically integrated elearning courses and a computer-based series of teaching sessions brought about some knowledge and attitude gain from baseline (table 3 ).

\section{Synthesis of barrier, facilitator and intervention studies}

Having identified 10 reports meeting our criteria as intervention outcome studies, we then went on to juxtapose these interventions with the barrier and facilitator studies identified in two systematic reviews previously conducted by the authors. ${ }^{10} 11$
Figure 2 outlines the number of studies included at various stages of this second, overarching review. Systematic and exhaustive searches identified 3329 citations in total. Retrieval, screening and classification of full reports had previously resulted in the identification of 27 studies addressing barriers and 15 studies that included facilitators. ${ }^{10} 11$ These were now joined by the 10 studies evaluating interventions to enhance systematic review uptake. ${ }^{28-37}$ Use of multiple data sources can enhance the credibility of findings. ${ }^{39}$ Intervention study characteristics were included in table 1 while barrier and facilitator study characteristics were described previously. ${ }^{10}{ }^{11}$ The synthesis of these barrier, facilitator 
Table 2 PubMed was searched from January 2011 to January 2014 using the advanced search facility

\begin{tabular}{llr}
\hline Search & Query & Items found \\
\hline 1 & systematic review AND facilitators AND knowledge uptake & 3 \\
2 & meta-analysis AND facilitators AND knowledge uptake & 3 \\
3 & systematic review AND enhance* AND knowledge uptake & 143 \\
4 & meta-analysis AND enhance* AND knowledge uptake & 4 \\
5 & systematic review AND facilitator* AND knowledge utilisation & 0 \\
6 & meta-analysis AND facilitator* and knowledge utilisation & 0 \\
7 & systematic review AND improve* AND knowledge utilisation & 18 \\
8 & meta-analysis AND improve* AND knowledge utilisation & 4 \\
9 & overview* OR review* AND intervention AND knowledge translation & 156 \\
10 & systematic review* OR meta-analys* AND intervention* AND evidence uptake & 56 \\
387 citations were returned by PubMed but no further relevant studies were identified &
\end{tabular}

and intervention studies, with the three most effective interventions listed first, is outlined in table 4.

\section{Decisionmaker's views}

Research indicates that the perceived barriers to the use of evidence from systematic reviews tend to vary. ${ }^{10}$ The most commonly investigated barriers were lack of use, lack of awareness, lack of access, lack of familiarity, lack of perceived usefulness, lack of motivation and external barriers related to the format and content of reviews and a prevailing negative organisational culture.

Perceived facilitators to the use of evidence from systematic reviews are also diverse. ${ }^{11}$ The five most commonly reported facilitators to uptake of evidence from systematic reviews were: the perception of systematic reviews as having multiple uses; a content that included benefits, harms and costs; a format with graded access and executive summary; training in use and peer-group support.

\section{Synthesis}

Table 4 shows the synthesis matrix which juxtaposes barriers and facilitators alongside the results of outcome evaluations. The three interventions having a statistically significant impact on at least one outcome measure are listed first. There were some matches but also significant gaps between what decisionmakers see as helpful to evidence uptake from systematic reviews and, on the other hand, soundly evaluated interventions that addressed both facilitators and barriers.

Three interventions, of low-to-moderate risk of bias, had statistically significant results on at least one outcome measure. These strategies included targeted messaging, educational visits and summaries of systematic reviews.

Tailored, targeted messaging addressed the specific barriers of limited access to, awareness of and familiarity with systematic reviews. Targeted messaging also built on enhancers of uptake such as increased choice of format, with web-based delivery and an overall improved access. A graded format takes into account the disparate information needs of various disciplines at different positions in an organisation. It addresses the concern that one size does not fit all.

Educational visits overcame and built on a wide range of factors. Knowledge barriers such as lack of access, lack of awareness and familiarity; attitudinal barriers such as limited motivation, perceived lack of usefulness and relevance; and external barriers such as an adverse organisational climate, were impacted on by this complex intervention. Increased access and training were among the facilitators of uptake of systematic reviews built on by this approach that also took into account the information needs of the target audience and their level of training.

Brief summaries of systematic reviews overcame the knowledge barriers of lack of access, lack of awareness and familiarity; attitudinal barriers of perceived lack of usefulness and relevance; and the external barrier of systematic reviews usually having a standard format for all readers, regardless of their level of training. Brief summaries facilitated the uptake of evidence from systematic reviews by providing a one-page, web-based, useful synopsis that took into account the information needs and time demands of the target audience.

A number of other promising interventions, not achieving statistically significant results, also overcame important barriers and built on a number of facilitators. A multifaceted educational intervention addressed a wide range of knowledge, attitude and external barriers, and also built on facilitators to produce substantial but non-significant knowledge and attitudinal gains. ${ }^{30}$ A patient manual addressed similar barriers and facilitators as did the brief summaries of systematic reviews. ${ }^{31}$

A further three studies using e-learning, addressed a similar number of barriers and facilitators. ${ }^{32} 34$ Each of the two computer-based interventions addressed the same factors in terms of number and content and brought about some non-significant, improvement between preassesment and postassessment. ${ }^{36} 37$

A number of issues were identified that had not been addressed by the effective or promising interventions. These were mainly facilitators and included building on the time-saving aspect of systematic reviews, their 
Table 3 Risk of bias assessment and results of intervention studies

\begin{tabular}{|c|c|c|c|c|}
\hline Study & $\begin{array}{l}\text { Risk of } \\
\text { bias }\end{array}$ & Primary measures & Outcome & Authors' conclusions \\
\hline Wyatt et $a P^{8}$ & Low & $\begin{array}{l}\text { Ventouse usage. Steroid usage. Suture usage. } \\
\text { Antibiotics usage and concordance of guidelines } \\
\text { with systematic review }\end{array}$ & $\begin{array}{l}\text { Overall baseline rate increased from } 43 \% \text { to } \\
54 \% \text {. Only one clinical practice improved } \\
\text { significantly }\end{array}$ & $\begin{array}{l}\text { Educational visits added little to } \\
\text { uptake of systematic review } \\
\text { evidence. Significant change in } \\
\text { ventouse delivery only }\end{array}$ \\
\hline Oermann et $a{ }^{29}$ & Low & $\begin{array}{l}\text { Awareness, understanding, usefulness, and } \\
\text { preferred mode of delivery of reviews }\end{array}$ & $\begin{array}{l}\text { Awareness improved significantly } \\
\text { ( } p=0.001) . \text { Understanding improved } \\
\text { non-significantly }\end{array}$ & $\begin{array}{l}\text { Short summaries of systematic } \\
\text { reviews improve awareness of } \\
\text { review evidence }\end{array}$ \\
\hline Dobbins et $a{ }^{\beta 3}$ & Low & $\begin{array}{l}\text { Use in a programme decisions and change in } \\
\text { healthy body weight promotion policies }\end{array}$ & $\begin{array}{l}\text { No significant effect for primary outcome } \\
(p=0.45) \text {. For policies, a significant effect for } \\
\text { targeted, tailored messages }(p<0.01) \text {. All } \\
\text { groups improved }\end{array}$ & $\begin{array}{l}\text { Targeted, tailored, messages are } \\
\text { more effective that knowledge } \\
\text { brokering and online registry }\end{array}$ \\
\hline Gulmezo-glu et $a{ }^{\beta 0}$ & Moderate & $\begin{array}{l}\text { Social support in labour MgSO4 for eclampsia. } \\
\text { Corticosteroids-preterm selective episiotomy. } \\
\text { Uterotonic use after birth. Breastfeeding on } \\
\text { demand. External cephalic version. Iron/folate } \\
\text { supplementation. Antibiotic use at caesarean } \\
\text { section. Vacuum extraction for assisted birth. } \\
\text { Knowledge of RHL. Use of RHL }\end{array}$ & $\begin{array}{l}\text { No consistent/substantive changes in } 10 \\
\text { clinical practices. RHL awareness }(24.8 \%- \\
65.5 \% \text { in Mexico, } 33.9-83.3 \% \text { in Thailand) } \\
\text { and use (4.8-34.9\% in Mexico and 15.5- } \\
76.4 \% \text { in Thailand) increased substantially } \\
\text { after the intervention }\end{array}$ & $\begin{array}{l}\text { Results were negative regarding } \\
\text { practices targeted, but there was } \\
\text { increased awareness, use of } \mathrm{RHL}\end{array}$ \\
\hline Harris et $a^{\beta 1}$ & Moderate & $\begin{array}{l}\text { Rates of flu vaccination, bone density testing, } \\
\text { increased satisfaction, improved communication, } \\
\text { reduced anxiety, improved quality of life }\end{array}$ & $\begin{array}{l}\text { No pattern of statistically benefit in primary } \\
\text { or secondary outcome measures but } \\
\text { virtually all trends favoured the intervention } \\
\text { group. High levels of use, little impact on } \\
\text { clinical practice }\end{array}$ & $\begin{array}{l}\text { Advantages for the intervention } \\
\text { were seen as trends }\end{array}$ \\
\hline Davis et $a \beta^{\beta 7}$ & Moderate & Knowledge gain, attitude gain & Similar results for attitude and knowledge & $\begin{array}{l}\text { Computer-based teaching as } \\
\text { effective as lecture-based }\end{array}$ \\
\hline Kulier et $a{ }^{34}$ & High & Change in knowledge and attitude scores & $\begin{array}{l}\text { On average, knowledge scores improved } \\
\text { significantly }(p<0.001) \text {. Attitudinal gains on } \\
\text { two questions only }(p=0.00, p=0.007)\end{array}$ & $\begin{array}{l}\text { E-learning about systematic reviews } \\
\text { can be harmonised across different } \\
\text { languages and specialities }\end{array}$ \\
\hline Davis et $a \beta^{\beta 6}$ & Moderate & $\begin{array}{l}\text { Knowledge gain } \\
\text { Attitude gain }\end{array}$ & $\begin{array}{l}\text { Difference between groups: }-0.5(95 \% \mathrm{Cl} \\
-1.3 \text { to } 0.3: p=0.24)\end{array}$ & $\begin{array}{l}\text { Computer-based teaching and } \\
\text { typical lectures have similar gains in } \\
\text { knowledge and attitude }\end{array}$ \\
\hline Kulier et al & Moderate & Change in knowledge and attitude scores & $\begin{array}{l}\text { The intervention group outperformed by } \\
\text { control group by } 3.5 \text { points }(95 \% \mathrm{Cl}-2.7 \text { to } \\
\text { 9.8) for knowledge gain: not statistically } \\
\text { significant }\end{array}$ & $\begin{array}{l}\text { Both groups had an improvement in } \\
\text { attitude and knowledge but the } \\
\text { intervention group had a tendency } \\
\text { to better performance }\end{array}$ \\
\hline Hadley et $a l^{35}$ & High & Knowledge gain & $\begin{array}{l}\text { Adjusted postcourse difference: only } 0.1 \\
\text { scoring points ( } 95 \% \mathrm{Cl} 1.2 \text { to } 1.4) \text { between } \\
\text { groups: no difference in improvement in } \\
\text { knowledge between groups }\end{array}$ & $\begin{array}{l}\text { E-learning and standard } \\
\text { classroom-based teaching both } \\
\text { improve knowledge }\end{array}$ \\
\hline
\end{tabular}

RHL, Reproductive Health Library. 


\section{Review question}

'What is known about the barriers, facilitators, and interventions impacting on uptake of systematic reviews?'

\section{Stage 1: Mapping and quality screening exercise}

Systematic and exhaustive searches identified 3,329 citations. Studies were included if they addressed barriers and facilitators to uptake of evidence specifically from systematic reviews, meta-analyses and the databases that contained them. Retrieval, screening, and classification of full reports resulted in the identification of 27 studies addressing barriers, 15 studies that included natural facilitators, and 10 studies evaluating interventions.

Non-intervention studies

Studies of decision makers' views
Intervention studies

Rigorous evaluation studies of interventions Focus on addressing impact on knowledge, attitude, behaviour and practice

\section{Stage 2: in-depth review}

Synthesis across study types to answer sub-question:

'To what extent do interventions overcome the barriers identified by decision makers and build upon the facilitators to uptake of evidence from systematic reviews?'

Non-intervention (views) studies

Application of inclusion criteria resulted in 27 studies addressing barriers and 15 identifying facilitators

Data extracted for description of characteristics and quality

Findings extracted

Findings synthesised to answer sub-question: 'What are the views on uptake of evidence from systematic reviews?'
Intervention studies (outcomes)

Application of inclusion criteria

resulted in 10 outcome studies

Data extracted for description of characteristics and quality

Findings extracted

Eight out of 10 studies: low-to-

moderate risk of bias

Findings synthesised to answer:

'What are the effects of interventions on uptake of systematic reviews?'

Figure 2 An overview of all stages of the review and the approach taken.

perceived ease of use, their importance relative to other sources of information and their ability to improve confidence. The added value of logos and the advantages of consistent presentation were not utilised as often as they might have been.

\section{DISCUSSION}

This study systematically identified interventions that enhance the uptake of evidence from systematic reviews. Previous reviews tend to focus on practical use of systematic reviews, ${ }^{2}$ rather than a more general uptake incorporating an increase in knowledge or a change in attitude. Previous overviews place an emphasis on use by specific decisionmakers such as policymakers ${ }^{8}$ or clinicians ${ }^{9}$ rather than including all stakeholders as occurs in this systematic review. Our review reported three interventions that had a statistically significant impact on at least one outcome measure rather than simply highlighting a positive trend. ${ }^{8}{ }^{9}$ Furthermore, our review did not base recommendations on studies deemed to have a low quality of evidence. ${ }^{9}$

Indeed, this synthesis differed from others in that it incorporated a second overarching review in order to 
Table 4 Synthesis matrix juxtaposing interventions, barriers and facilitators

\begin{tabular}{|c|c|c|}
\hline Interventions & Barriers addressed & Facilitators addressed \\
\hline Tailored, targeted messaging & Lack of access & A graded format \\
\hline \multirow[t]{2}{*}{ Dobbins et $a \beta^{\beta 3}$} & Lack of awareness & Delivery: Web-based \\
\hline & Lack of familiarity & $\begin{array}{l}\text { Consistent presentation } \\
\text { Increased access }\end{array}$ \\
\hline Educational visits & Lack of use & Usefulness \\
\hline \multirow[t]{7}{*}{ Wyatt et $a R^{28}$} & Lack of awareness & Training \\
\hline & Lack of access & Peer-group support \\
\hline & Lack of familiarity & Delivery: CD ROM \\
\hline & Lack of usefulness & Perceived ease of use \\
\hline & Lack of motivation & Position in an organisation \\
\hline & External barriers & Organisational value \\
\hline & & Motivation, Increased access \\
\hline Brief summaries & Lack of awareness & Usefulness \\
\hline \multirow[t]{6}{*}{ Oermann et $a^{{ }^{9}}$} & Lack of access & Highlighted content \\
\hline & Lack of familiarity & A graded format \\
\hline & Lack of usefulness & Delivery: Web-based \\
\hline & External barriers & Position in an organisation \\
\hline & Lack of relevance & Increased access \\
\hline & Ignore target audience & \\
\hline Multifaceted educational & Lack of use & Training \\
\hline intervention & Lack of awareness & Peer-group support \\
\hline \multirow[t]{8}{*}{ Gulmezoglu et $a^{\beta 0}$} & Lack of access & Delivery: Web-based \\
\hline & Lack of familiarity & Organisational value \\
\hline & Lack of usefulness & Motivation \\
\hline & Lack of motivation & Increased access \\
\hline & External barriers & Familiarity with computers \\
\hline & Lack of relevance & \\
\hline & Lack of implementation strategies & \\
\hline & Ignore target audience & \\
\hline Manual of Cochrane reviews & Lack of use & Usefulness \\
\hline \multirow[t]{8}{*}{ Harris et $a \beta^{\beta 1}$} & Lack of awareness & Highlighted content \\
\hline & Lack of access & Format: summaries \\
\hline & Lack of familiarity & Delivery: paper-based \\
\hline & Lack of usefulness & Ability to improve confidence \\
\hline & External barriers & Position in an organisation \\
\hline & Lack of relevance & Motivation \\
\hline & Ignore target audience & Increased access \\
\hline & Lack of implementation strategies & \\
\hline E-learning course & Lack of use & Usefulness \\
\hline Kulier et $a^{\beta 2}$ & Lack of awareness & Training \\
\hline Kulier et $a \beta^{34}$ & Lack of access & Peer-group support \\
\hline \multirow[t]{7}{*}{ Hadley et $a 1^{35}$} & Lack of familiarity & Delivery: Web-based \\
\hline & Lack of usefulness & Position in an organisation \\
\hline & External barriers & Motivation \\
\hline & Lack of relevance & Increased access \\
\hline & Lack of implications & Increased confidence \\
\hline & Ignore target audience & Organisational values \\
\hline & Lack of implementation strategies & \\
\hline Access to online registry & Lack of awareness & Delivery: Web-based \\
\hline Dobbins et $a^{\beta 3}$ & Lack of access & Increased access \\
\hline Knowledge brokers & Lack of awareness & Usefulness \\
\hline \multirow{7}{*}{ Dobbins et $a /^{\beta 3}$} & Lack of access & Graded format \\
\hline & Lack of familiarity & Training \\
\hline & Lack of usefulness & Peer-group support \\
\hline & Lack of use & Delivery: Web-based \\
\hline & Lack of relevance & Consistent presentation \\
\hline & Lack of implications for practice & Position in an organisation \\
\hline & Lack of implementation strategies & Organisational value \\
\hline
\end{tabular}


Table 4 Continued

\begin{tabular}{lll}
\hline Interventions & Barriers addressed & Facilitators addressed \\
\hline & Ignore target audience & Increased access \\
& Lack of workshop attendance & Lack of positive climate \\
Computer-based (CD-ROM) & Lack of use & Usefulness \\
session & Lack of awareness & Training \\
Davis et $a \beta^{36}$ & Lack of access & Peer-group support \\
Davis et $a$ P $^{9}$ & Lack of familiarity & Delivery: CD ROM \\
& Lack of usefulness & Position in an organisation \\
& External barriers & Organisational value \\
& Lack of implications for practice & Increased access \\
& Lack of implementation strategies & Familiarity (computers) \\
\hline
\end{tabular}

illustrate the extent to which the detected interventions addressed barriers and facilitators impacting on systematic review uptake. Importantly, this allowed our mixedmethods design, to generate recommendations about interventions to enhance review uptake.

The evidence for the effectiveness of interventions to improve systematic review uptake is variable. Three interventions, of low-to-moderate risk of bias, had a statistically significant advantage over a comparison on at least one outcome measure. These interventions included educational visits, short summaries of systematic reviews and targeted messaging. Other interventions such as interactive workshops produced 'substantial' benefits, while clinically integrated e-learning courses and computer-based series of teaching sessions brought about some knowledge or attitude gain from baseline. No study demonstrated a significant impact directly on patient care.

Unlike other reviews, this study adopted a wider perspective through inclusion of studies of decisionmaker's views as well as outcome effectiveness studies. Taking account of a decisionmaker's preferences and abilities is important. ${ }^{39}$ Juxtaposing perceived barriers and facilitators alongside effectiveness studies allowed us to examine the extent to which the needs of decisionmakers had been adequately addressed by the evaluated interventions. To some extent they had. Lack of access, awareness and familiarity were frequently overcome as barriers. However, fewer of the identified facilitators appear to have been built on by the interventions.

We recommend three interventions: tailored, targeted messaging, systematic review summaries and educational visits. These address a range of factors impacting on review uptake. Some approaches however require additional work before they can be recommended for practice. ${ }^{40}$ Interventions such as e-learning, computer-based learning, multifaceted educational interventions, an on-line registry and the use of a knowledge broker are strategies that need to be developed further.

Many of the gaps in the evidence about uptake of systematic reviews tended to be in relation to building on identified facilitators. Despite a wide search, we found few evaluations of strategies that emphasised the timesaving aspect of systematic reviews, their importance relative to other sources of information and their ability to improve self-confidence in using evidence. New interventions need to be developed that build on these enhancers of uptake.

A surprising finding was that, despite the wider range of barriers and facilitators addressed by use of a knowledge broker, this intervention was not as effective as targeted, tailored messaging. ${ }^{33}$ The more complex intervention was not more effective. That targeted, tailored messaging overcame and built on a smaller number of barriers and facilitators suggests that it is not the number of factors addressed that is central but their relevance and intensity.

\section{Limitations}

A frequent disappointment in the conduct of systematic reviews is the relative paucity of published primary studies on which to base the review. ${ }^{41}$ We found just 10 intervention studies in all, with 8 of these of moderate-to-low risk of bias. Identification of published studies on evidence uptake is difficult because they are poorly indexed and scattered across generalist and specialist journals. Some publications may have been missed, though an extensive search was conducted using over 19 databases. Furthermore, reporting was sometimes incomplete so that data extraction was problematic. $^{42}$

Important methodological limitations and inconsistencies among the studies identified make it extremely difficult, currently, to justify policy action taken on the basis of evidence alone. ${ }^{20}$ The limitations of our review largely reflect the limitations of the literature reviewed. Undertaking reviews in this area is difficult because of the complexity inherent in the interventions, the variability of the methods used, and the difficulty of generalising findings across healthcare settings.

The impact of the interventions was not consistent across users, settings or behaviours. Positive studies had 
just one or two of many outcome measures that yielded a significant result. Some studies presented a positive trend, others statistically significant outcomes. Certain interventions appeared to improve knowledge and attitudes, and to a lesser extent, performance. None were shown to impact on patient outcomes. This issue of patient-centred outcomes is likely to become more prominent in the coming years. ${ }^{15}$ Although the current evidence base is incomplete, this synthesis does however provide valuable insights into the likely effectiveness of different interventions.

\section{Implications for research}

We need to standardise reporting of trials of interventions to improve professional performance. A broad framework should be developed for designing and selecting appropriate interventions across a wide range of professional activities in which gaps between evidence and practice are found. ${ }^{43}$ Both clinical practice and also more patient outcome data are required.

Barriers and facilitators can be used as starting point for intervention relevance. ${ }^{13}$ This review can be considered a resource. The conclusions suggest recommendations for a research agenda based on appropriate and feasible interventions that could be evaluated for their effectiveness.

Barriers and facilitators that were not addressed adequately in any of the intervention evaluations led us to draw conclusions about opportunities for new interventions and their subsequent evaluation. We have noted that several barriers to, and facilitators of, uptake of systematic reviews have received little attention. Reviews are perceived as having a limited range, a narrow focus, are poorly promoted and not updated frequently enough. ${ }^{10}$ The medicolegal relevance of systematic reviews has not been highlighted sufficiently. Further work is needed to develop and evaluate interventions which modify or remove identified barriers and build on highlighted facilitators.

\section{Implications for practice}

This framework allows reviewers to address some of the criticisms of systematic reviews of controlled trials by taking into account the social and structural influences on their uptake. ${ }^{13}$ It is important to carefully select the intervention most likely to be effective in the light of the diagnosed problem. ${ }^{44}$ Choosing the right strategy is an essential component of developing evidence-based practice and ultimately improving patient care. ${ }^{45}$ We need to focus more on impacting on patient satisfaction and quality of life. ${ }^{46}$ Clinically integrated interventions are also required. ${ }^{47}$

Presentation is as important as results. Little attention has been paid to the format of a review. ${ }^{5}$ The reviews are often technical, contain complex statistics and are written in an academic style. The evidence suggests that systematic reviews should be presented in an easily understood way with information accessed in a graded manner. The identification of a take-home message is important.

The aim here was to place the different interventions in perspective. ${ }^{48}$ It is important to consider the target audience, their values and preferences while linking the key message to the level of the decisionmaker's training. We should refocus efforts on improving and promoting graded access to summaries of evidence.

\section{CONCLUSION}

We recommend three interventions: tailored, targeted messaging, systematic review summaries and educational visits. These address a range of identified factors impacting on review uptake. Other interventions, such as e-learning approaches, need to be developed further. New interventions need to be devised that build on neglected facilitators of uptake.

This review has added value compared with conventional reviews of effectiveness. ${ }^{13}$ The advantage lies in the ability to examine systematically a much wider literature so to suggest recommendations for practice. A conventional review of effectiveness in this area would have been able to draw on 10 outcome evaluation reports to generate conclusions about effectiveness. We were able to draw on an additional 27 studies encompassing decisionmaker's views about barriers and 15 studies targeting facilitators.

We addressed not just effectiveness but also appropriateness. The approach utilised a larger proportion of research evidence relevant to the review question. The evidence synthesised here is important to a broad sweep of institutions concerned with evidence uptake in general and systematic review uptake in particular.

Contributors JW, CB and MC were involved in the conceptualisation, conduct, preparation and writing up of the research. All authors made a substantial contribution to the design, acquisition, analysis and interpretation of data. All authors were involved in the drafting and revision of the article for intellectual content and all approved the final version.

Funding This research received no specific grant from any funding agency in the public, commercial or not-for-profit sectors.

Competing interests None.

Provenance and peer review Not commissioned; externally peer reviewed.

Data sharing statement Additional information, including the protocol, examples of the search strategy, and risk of bias tables for each individual study and bias across groups, is available from the corresponding author at john.wallace@wadh.oxon.org.

Open Access This is an Open Access article distributed in accordance with the Creative Commons Attribution Non Commercial (CC BY-NC 4.0) license, which permits others to distribute, remix, adapt, build upon this work noncommercially, and license their derivative works on different terms, provided the original work is properly cited and the use is non-commercial. See: http:// creativecommons.org/licenses/by-nc/4.0/

\section{REFERENCES}

1. Innvaer S, Vist G, Trommald M, et al. Health policy-makers' perceptions of their use of evidence: a systematic review. J Health Serv Res Policy 2002;7:239-44.

2. Murthy L, Shepperd S, Clarke MJ, et al. Interventions to improve the use of systematic reviews in decision-making by health system 
managers, policy makers and clinicians. Cochrane Database Syst Rev 2012;9:CD009401.

3. Knottnerus JA, Tugwell P. 'The evidence base of taming continuously proliferating evidence'. J Clin Epidemiol 2012:65:1241-2.

4. Sackett D, Rosenberg WC, Muir Gray JA, et al. Evidence based medicine: what it is and what it isn't. BMJ 1996;312:71.

5. Tetzlaff J, Tricco A, Moher D. Knowledge synthesis. In: Straus S, Tetroe J, Graham ID, eds. Knowledge translation in health care. UK: Wiley-Blackwell, BMJ Books, 2009:15-34.

6. Dawes M, Sampson U. Knowledge management in clinical practice: a systematic review of information seeking behavior in physicians. Int J Med Infor 2003;71:9-15.

7. Lavis J, Davies H, Oxman A, et al. Toward systematic reviews that inform health care management. J Health Serv Res Policy 2005;10 (Suppl 1):35-48.

8. Perrier L, Mrklas K, Lavis JN, et al. Interventions encouraging the use of systematic reviews by health policymakers and managers: a systematic review. Implement Sci 2011;6:43.

9. Perrier L, Mrklas K, Shepperd S, et al. Interventions encouraging the use of systematic reviews in clinical decision-making: a systematic review. J Gen Intern Med 2011;26:419-26.

10. Wallace J, Nwosa B, Clarke J. Barriers to the uptake of evidence from systematic reviews and meta-analyses: a systematic review of decision makers' perceptions. BMJ Open 2012;2:e001220.

11. Wallace J, Byrne C, Clarke M. Making evidence more wanted; a systematic review of facilitators to enhance the uptake of evidence from systematic reviews and meta-analyses. Internal J Evid Based Healthcare 2012;10:338-46.

12. Pope C, Mays N, Popay J. Synthesizing qualitative and quantitative research. UK: McGraw-Hill, 2007.

13. Oliver S, Harden A, Rees R, et al. An emerging framework for including different types of evidence in systematic reviews for public policy. Evaluation 2005;11:428-46.

14. Noyes J, Popay J, Pearson A, et al. Qualitative research and cochrane reviews. In: Higgins JP, Green S, eds. Cochrane handbook for systematic reviews of interventions. Chichester, UK: John Wiley \& Sons, 2008:571-92.

15. Gartleher G, Flamm M. Is the Cochrane Collaboration prepared for the era of patient-centred outcomes research? Cochrane Database Syst Rev 2013;3:ED000054.

16. Wong G, Greenhalgh T, Westthorp PG, et al. RAMESES Publication Standards: meta-narrative review. BMC Med 2013;11:20.

17. Shepherd J, Harden A, Rees R, et al. Young people and healthy eating: a systematic reviews on research on barriers and facilitators. Health Educ Res 2005;21:239-57.

18. Cochrane Effective Practice and Organisation of Care Group: Data Collection Checklist. EPOC resources for review authors Revised 2002. http://www.epoc.cochrane.org/en/handsearchers.html

19. Chaillet N, Dube E, Dugasm M, et al. Evidence-based strategies for implementing guidelines in obstetrics: a systematic review. Obstet Gynecol 2006;108:1234-45.

20. Joly A, Ngueng Feze I, Simard J. Genetic discrimination and life insurance: a systematic review. BMC Medicine 2013;11:25.

21. Grol R, Grimshaw J. From best evidence to best practice: effective implementation of change in patients' care. Lancet 2003;362:1225-30.

22. Baker R, Camosso-Stefinovic J, Gillies C, et al. Tailored interventions to overcome identified barriers to change: effects on professional practice and health care outcomes. Cochrane Database Syst Rev 2010;(3):CD005470.

23. Anglin RE, Samaan Z, Walter SD, et al. Vitamin D deficiency and depression in adults: systematic review and meta-analysis. $\mathrm{Br} J$ Psychiatry 2013;202:100-7.

24. Thomas J, Harden A, Oakley A, et al. Integrating qualitative research with trials in systematic reviews. BMJ 2004;328:1010.

25. Brunton G, Harden A, Rees R, et al. Children and physical activity: a systematic review of barriers and facilitators. London: EPPI-Centre, Social Science Research Unit, Institute of Education, University of London, 2003.
26. Rees R, Harden J, Shepherd G, et al. Young people and physical activity: a systematic review of barriers and facilitators. London: EPPI-Centre, Social Science Research Centre, 2001.

27. Harden A, Rees J, Shepherd G, et al. Young people and mental health: a systematic reviews of barriers and facilitators. London: EPPI-Centre, Social Science Research Centre, 2001.

28. Wyatt J, Paterson-Brown S, Johanson R, et al. Randomized trial of educational visits to enhance use of systematic reviews in 25 obstetric units. BMJ 1998;317:1041-6.

29. Oermann M, Roop J, Nordstrom C, et al. Effectiveness of an intervention for disseminating Cochrane reviews to nurses. Medsurg Nurs 2007;16:6.

30. Gulmezoglu AM, Lnager A, Piaggo G, et al. Cluster randomised trial of an active multi-faceted educational intervention based on the WHO Reproductive Health Library to improve obstetric practices. BJOG 2007;114:16-23.

31. Harris M, Smith BJ, Veale A, et al. Treatments: a controlled trial of outcomes. Providing patients with reviews of evidence about COPD. Chron Respir Dis 2006;3:133.

32. Kulier R, Coppus S, Zamora J, et al. The effectiveness of a clinically integrated e-learning course in evidence-ased medicine: a cluster randomised controlled trial. BMC Med Educ 2009;9:21.

33. Dobbins $\mathrm{M}$, Hanna S, Ciliska D, et al. A randomized controlled trial evaluating the impact of knowledge translation and exchange strategies. Implementation Sci 2009;4:61.

34. Kulier R, Hadley J, Weinbrenner S, et al. Harmonising Evidence-based medicine teaching: a study of the outcomes of e-learning in five European countries. BMC Med Educ 2008;8:27.

35. Hadley J, Kulier R, Zamora J, et al. Effectiveness of an e-learning course in evidence-based medicine for foundation (internship) training. J R Soc Med 2010;103:288-94.

36. Davis J, Crabb S, Roger E, et al. Computer-based teaching is as good as face to face lecture-based teaching of evidence based medicine: a randomized controlled trial. Med Teach 2008;30:302-7.

37. Davis J, Chyssafidou E, Zamora J, et al. Computer-based teaching is as good as face to face lecture-based teaching of evidence based medicine: a randomised controlled trial. BMC Med Educ 2007;7:23.

38. Burton LJ, Tyson S, Mcgovern A. Staff perceptions of using outcome measures in stroke rehabilitation. Disabil Rehabil 2013;35:828-34.

39. Lawrence V, Fossey J, Ballard C, et al. Improving quality of life for people with dementia: making psycho-social interventions work. BJP 2012;201:344-51.

40. Van Oort L, Van Den Berg T, et al. Preliminary state of development of prediction models for primary care physical therapy: a systematic review. J Clin Epidemiol 2012;65:1257-66.

41. Matson J. Narrative overview of systematic reviews and meta-analyses: evidence on many treatments for psychopathology in people with developmental disabilities is limited. Evid Based Ment Health 2013;16:44.

42. Stewart CG, Omar O, Milensu S, et al. A systematic review finds that prediction models for chronic kidney were poorly reported and often developed using inappropriate methods. J Clin Epidemiol 2013;66:268-77.

43. Oxman D, Thomson MA, Davis D, et al. No magic bullets: a systematic review of 102 trials of interventions to improve professional practice. Can Med Assoc 1995;153:1423-31.

44. Eastman G, O'connell B, Gardner A. Selecting the right integration of research into practice strategy. J Nurs Care Qual 2008;23:258-64.

45. Nabulsi M, Harris J, Letelier L, et al. Effectiveness of education in evidence-based healthcare: the current state of outcome assessments and a framework for future developments. Int $\mathrm{J}$ Evid Based Healthcare 2007:5:468-76.

46. Coomary A, Khan K. What is the evidence that postgraduate teaching in evidence based medicine changes anything? A systematic review. BMJ 2004;329:1017.

47. Mccoll A, Smith H, White P, et al. General practitioner's perceptions of the route to evidence based medicine: a questionnaire survey. BMJ 1998:316:361-5

48. Leucht S, Hierl S, Kissling W, et al. Putting the efficacy of psychiatric and general medicine medication into perspective: review of meta-analyses. Br J Psychiatry 2012;200:97-106. 